\title{
An Empirical Study on Effectiveness of Training Programs among Women Employees in Public and Private Sector Banks
}

Maninder Kaur*

\begin{abstract}
Women have played a pivotal role in the global economy, but their contributions have not been given due recognition. The global financial landscape has had a significant transformation and it high time that the society realized that women are equal stakeholders in the revival of the global economy. As a part of such an effort, this study is an attempt to understand and compare the patterns of participation of women in private and public sector banks. It is also an attempt to measure the effectiveness of training programmes with a particular reference to women employees in private and public sector banks and how training contributes towards the growth of the banks. Thus this study is different from the previous studies in this arena.
\end{abstract}

\section{Introduction}

There is a Chinese proverb, "Women hold up half the sky" however, the identity and voice of these women are neither visible nor audible.

The global financial landscape has had a significanttransformation, and it is now the right time for new identities and voices to make society realize that women are equal stakeholders in the revival of

\footnotetext{
*Associate Professor, Shri Guru Tegh Bahadur Institute of Management and Information Technology (SGTBIMIT), New Delhi 110033, India; manip_jp@yahoo.com
} 
the global economy. The reshaping of the world financial system is an opportune moment to increase the role of women in the global economy.

No doubt, women have played a pivotal role in the global economy, but their contributions have not been given due recognition. This study is an attempt to understand and compare the patterns of participation of women in private and public sector banks.

This paper attempts to present a review of the various studies which have a direct and indirect bearing on the role of women in the financial sector/services and the initiatives that have been taken to enhance or improve their participation. They may also have been achieved through adequate training and development programmes initiated specifically keeping in mind the female impact. Thus it is important to evaluate the opportunities available and availed by the female folk. Training and development activities have been receiving unprecedented attention in the banking sector.

In this study, an attempt will be made to study the effectiveness of training programmeswith a particular reference to women employees among private and public sector banks and how training contributes for growth of the banks. Thus this study is different from the previous studies in this arena.

Studies suggest that trainings have not only an impact on the individual but also organizational performance. It becomes imperative to study what is the perception of trainers regarding training programmes since attempts have been made to study the trainee's perception in earlier studies. It concerns with two public sector banks and two private sector banks. Most of the studies have focused on either one of the sectors of banks. In this study, both public and private sector banks have been taken into account so that a comparative analysis can be done on the perceptions of trainers and trainees/employees in banking.

Technology has aided banking sector to become more secure, fast, accurate and also time-saving. ATMs, Mobile Banking, SMS Banking and Net Banking are instances of the way in which technology can simplify and popularize banking. 
Customers are offered a bouquet of services in today's banking system. The financial market is extremely competitive. With the intense competition that banks currently face, retaining existing customers and attracting new customers is more challenging and more important than ever.

Employee training has always been important in a bank. Because of all the laws and regulations that impact every aspect of banking, it is not prudent for a bank employee to be assigned a job and told just to do it. The employee must be trained on what the appropriate way to do a job is and what is considered as an inappropriate way. Moreover, an employee must be trained to learn the bank's methodology. Because of turnover in bank personnel, every bank has employees that previously worked for other banks. And those employees bring with them totally different policies and procedures regarding how a specific task should be accomplished. Without training, a bank would soon have 100 employees trying to accomplish the same task in 100 different ways. That would only lead to chaos. Because of the need for conformity and compliance with the regulations, banks have always had training programs for employees. Now, those training programs have added importance. But above all, the evaluation of the effectiveness of training at the workplace is to be valued more. In this study an effort has been made towards the same.

The primary objective of this research articleis to get the factual information of the importance and effectiveness of training from the point of view of women employees in banking scenario.

The secondary objective of the work is to outline and understand the impact of training strategies of the banks which would be helpful in enhancing the contribution of training in achievement of organizational goals and development.

\section{Review of Related Literature}

According to Ashok Gopal, Ester Martinez \& Rajlakshmi Saikia (2012) companies that effectively engage their employees will be better prepared for challenges during ups and down. The speed of change have a huge impact on how people interact, learn and 
collaborate inside and outside the workplace, and this demands a fresh look at managing talent with adequate training prospects and learning innovations.

Recent empirical studies typically find that training increases both wages and performance and, consistent with theory grounded in imperfect labour markets, also finds evidence of a wedge between wages and productivity effects and that employees and employers share benefits from training. (Ballot et al., 2006; Dearden et al., 2006; Sepulveda, 2010).

Athar Mahmood (2011)has found that training has been receiving unprecedented attention in the banking sector. The paper contributes to the area of management by helping understand what the trainees want from a training programme and its implications for managements, particularly in banking sector.

All training programs are meant to maintain, update and upgrade one's skills throughout one's employment. In several fields and areas, including management, these training programs are known as professional development programs Miller (2009).

Banerjee (2009) says that employee satisfaction gets the productivity, quality, pride, and creativity. Keeping morale high among workers can be of tremendous benefit to any company.

Survey by European Foundation for the Improvement of Living and Working Conditions (2007): From the proposed independent work-related issues, job autonomy emerged as having a strong and clear correlation with job satisfaction: more autonomy in a job leads to higher job satisfaction among respondents.

\section{Objective of Study}

To identify the general level of effectiveness of various training programs among women employees of the bank.

To identify the distinctive features of training programs in different banks inorder to achieve organizational effectiveness as a whole.

Objectives set were based on the following parameters to be studies. 


\section{Main targeted objectives are}

1. To analyze the effectiveness of training among women employees in private and public sector banks in metro city i.e. New Delhi.

2. To find the association between effectiveness of training and productivity of banks.

3. To evaluate the effectiveness of training programme in enhancing the role of women in banks.

\section{Hypotheses}

$\mathrm{H}_{1}$ The training programmes in public or private sector banks are same and have same perspective with regards to training procedure designed for women

$\mathrm{H}_{2}$ Training Programme gives positive impact on the growth of the banks.

$\mathrm{H}_{0}$ The training programmes in public or private sector banks are different and have different perspective with regards to training procedure designed for women

$\mathrm{H}_{0}$ Training Programme does not give positive impact on the growth of the banks.

\section{Importance of Study}

While the development and utilization of human resources is emerging as a core policy issue in all countries in the 21st Century, development and utilization of female human resources is also a policy issue that is importantly emphasizedin order to improve the national competitiveness and quality of life of the women. When we look into various government policies (such as the "Fundamental Plan for Development of National Human Resources", "The Second Fundamental Plan on Policies on female", and the "Law on Equality in Gender Employment"), employed female workers, dedicated housewives, and highly educated employed female are the key subjects of the policies on the development of female human resources.As per the data published by the 2011 census, India has managed to achieve an effective literacy rate of 74.04 percent in 2011, and the country's literacy rate 
stood at 64.8 percent. The most notable thing that came across in the 2011 census is the sharp rise in the literacy of females over males. This research focuses on the development of the working ability of employed female workerswith respect to the subjects of policy on female human resources. Specific goals of the research are as follows:

First, what is the recent trend in training and development for female employees in corporations?

Second, woman employees' reaction towards training and

Third, the effect of that reaction back at workplace.

Women constitute nearly one-half of the world's population having enormous potential but are being underutilized or unutilized for the economic development of the nation. This research article is an attempt to present the findings of an exploratory study carried out in the banking sector with the aim of shedding light onto the principles and practice of employee development within business units at a branch level with regards to gender specific.

Thus, the primary purpose of this study is to investigate the influence of mandatory training assignment on female trainees' motivation to learn, and to examine the mediating role of trainees' perceived importance of the training program on women employees in the bank.

\section{Research Methodology \& Design}

"Methodology is the key to any survey."

Primary hand/First-hand data:

1. Structured questionnaire - open ended

2. Interview method

3. Observation

It is primarily qualitative since the aim was to uncover women's views and experiences of State Bank of India, Punjab and Sind Bank(Public Sector Banks) and ICICI, HDFC Banks (Private Sector Banks) corroborated by documentary and quantitative data sources. In total 97bank branches and their extension counters of 
State Bank of India, Punjab and Sind Bank ICICI and HDFC banks situated in New Delhi were studied.

Primary data were collected from fieldwork conducted in New Delhi for six months, and this was combined with secondary data that were collected from several conventional sources. This research study draws mainly on the qualitative data set, although a summary is providedfor some of the main results from the questionnaire survey.

\section{Research Design}

\section{Locale of study}

The study was conducted in various branches of State Bank of India, Punjab and Sind Bank, ICICI and HDFC Banks situated in Delhi.

\section{Sampling Method and Sample Size}

The respondents were selected from 97 branches in all randomly by lottery method and then the questionnaire was sent to each branch for finalization. Keeping in mind the profile of the employees, respondents were selected using judgemental sampling.

To achieve the objective of the study, 300 surveys were sent to various respondents. Out of the 300 surveys, 270were responded to, posting an impressive response rate of $80 \%$. Out of 270,20 questionnaires were found to be incomplete, 9questionnaireswere vague and ambiguous and therefore discarded, and thus only 241 were evaluated and analysed.

The questionnaire was distributed among employees of various banks and later on were sorted out on the basis of gender required to be studied.

\section{Statistical Tool Used}

The questionnairewas based on 7-point Likert scale

1-Strongly agree, 2-Agree, 3-Somewhat Agree,4-No opinion, 5Somewhat Disagree, 6-Disagree, 7-Strongly disagree.

The questionnaire was divided into 4main sections (including demographic section): 
Demographics, Performance based payment, Pay and Fringe Benefits factor, Job Training \& Job Satisfaction, Job Evaluation.

The questionnaire section contained approx 10 questions in all covering job facets such as salary, fringe benefits and importantly "the learning opportunity" i.e. the Training.

\section{Data Analysis and Results}

For analysis of data Percentage Analysis and Stata 10.1 software was used. STATA -Data Analysis and Statistical Programs is an interactive data analysis program that runs on a variety of platforms. It can be used for both simple and complex statistical analyses. We have tried to analyze the data by running Poission Regression followed by Marginal effect of the variables and the alternate methodology i.e. Ordered Probit as total number of our responses were count variables. We have also used Robust method to understand the level of significance too.

This isbasically a qualitative and relative study for which a tested questionnaire was used.

\section{Research Limitations / Implications}

While researching and interviewing employees of different banks I came across few limitations like:-

- The training programs undertaken by different banks were not available easily and were termed confidential.

- Few banks did not allow its employees to disclose their policies and procedures.

- At times employees working in banks are not interested in undertaking training processes unless financially motivated.

- In few bank branches, training programs are not taken seriously because of lesser staff and heavy workload. Also, often training letter received from head office were suppressed in one way or the other. 
- The sample was based on the banks in Metropolitan town, New Delhi and hence the opinion of people living in suburban/rural areas could not be obtained.

- Lack of cooperation from employees of some departments to fill the questionnaire. The respondents specially few women cadre were reluctant to fill the questionnaire.

- This study was conducted only in the branch offices and not the controlling offices or headquarters.

- The survey was done only of the permanent women employees of the bank. Contractual/ad-hoc employees were not included in the study.

\section{Evaluation of Training programmes}

Evaluation of various programmesis done by making abilities and power to assess and ascertain women participation in various activities. To evaluate the education and work opportunity available for women and to access the role of women in decision making on important issues concerning the job perspective.

This paper focuses on the short term and long term enhancement of productivity as a result of various training programs as adopted in the business world being goals as an important variable. One should understand the organization's goals to develop training goals that help accomplish the business goals of the organisation.

Various techniques to stimulate training effectiveness to increase the efforts in evaluating training programs based on various parametric steps are identified.

As specified in the later part of the study it has notified the work of different researchers pointing to four main parameters to evaluate any trainingprogramme:

Reaction - Refers to third section of questionnaire i.e. Training need analysis and importance;

Learning - Refers to fourth section of questionnaire i.e. Training and Evaluation; 
Behavior - Refers to First and second section in relevance to third section as well i.e. Aspects of job satisfaction with performance based payment;

Results - Refers to fourth section in relevance to third i.e. leaning of training to be transferred at workplace, enhancing performance and, in turn, the pay.

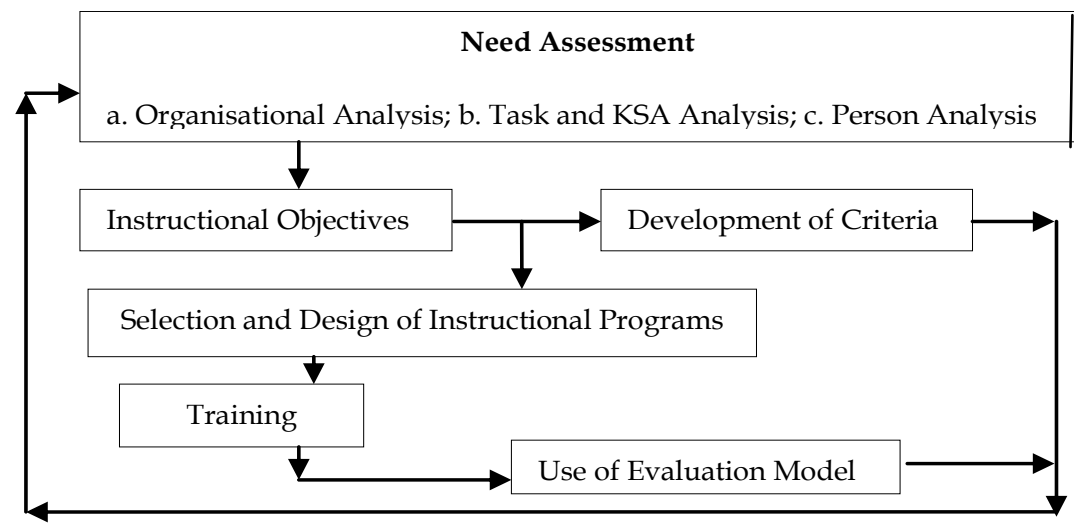

Fig: 1: An Instructional System |Needs Assessment, Training and Development and Evaluations

Source: Adopted from I L Goldstein (1993) Training in Organizations

\section{Data Analysis and Interpretation}

Table Depicting the Mean and Standard Deviation of Dependent Varibles of Public and Private Sector Bank under Study

\begin{tabular}{|l|r|r|r|r|}
\hline \multicolumn{3}{|c|}{ Public Sector Bank } & \multicolumn{2}{c|}{ Private Sector Bank } \\
\hline & \multicolumn{1}{|c|}{ Mean } & \multicolumn{1}{c|}{ S.D. } & Mean & \multicolumn{1}{c|}{ S.D. } \\
\hline Pir & 1.916667 & 0.985915 & 1.969072 & 1.045363 \\
\hline Ptr & 2.444444 & 0.867258 & 2.494845 & 0.80524 \\
\hline Phpy & 2.333333 & 1.017332 & 2.886598 & 1.289996 \\
\hline probipy & 2.395833 & 1.258364 & 2.546392 & 1.283068 \\
\hline trnges & 1.6875 & 0.79745 & 1.917526 & 1.006956 \\
\hline knptrng & 1.875 & 0.835196 & 1.762887 & 0.826302 \\
\hline trngcgw & 2.631944 & 1.4179 & 2.484536 & 1.283821 \\
\hline Jrs & 2.604167 & 1.044466 & 2.309278 & 1.14892 \\
\hline Fbp & 2.604167 & 1.444637 & 2.402062 & 1.247162 \\
\hline Bpym & 2.847222 & 1.400896 & 2.865979 & 1.426161 \\
\hline promd & 2.652778 & 1.323903 & 2.525773 & 0.137365 \\
\hline
\end{tabular}


$\mathrm{H}_{\mathrm{o}}$ The mean number of training programmes in public and private sector banksare same

H1 The mean number of training programmes in public is greater than mean number of training programmes in the private sector banks

In order to evaluate the variable of total number of trainings attended by the respondents with our policy variable i.e. the evaluation of productivity training being conducted by banks we did One tail T-Test and found that there is a significant difference in the number of training programmes conducted by public sector banks and private sector banks with respect to the women employees. It is statistically significant at $5 \%$ level of significance. So null hypothesis is rejected. There exists a difference in the number of trainings being conducted by two different sector banks for women. The difference may be pertinent due to $n$ number of reasons, may be because of the policy matters or rules and regulations of the banks. While nowadays the hardcore competition is evident in the global scenario market too, so to keep abreast with the changespublic sector banks are trying to keep up withthe private sector banks. However, the conduct of training programs as far as the gender aspect is concerned attention needs to be paid to.

Two-sample $t$ test with equal variances

\begin{tabular}{|c|c|c|c|c|c|c|}
\hline Group & Obs & Mean & $\begin{array}{l}\text { Std. } \\
\text { Err. }\end{array}$ & Std. Dev. ] & $\begin{array}{c}\text { [95\% Conf. } \\
\text { Interval] }\end{array}$ & \\
\hline 0 & 144 & 5.57639 & 0.34865 & 4.183852 & 4.887207 & 6.26557 \\
\hline 1 & 97 & 4.57732 & 0.35623 & 3.508428 & 3.870215 & 5.28442 \\
\hline combined & 241 & 5.17427 & 0.25438 & 3.948987 & 4.673178 & 5.67537 \\
\hline diff & & 0.99907 & 0.51576 & -0.0169549 & 2.015093 & \\
\hline \multicolumn{6}{|c|}{ diff $=$ mean $(0)-$ mean $(1)$} & \\
\hline \multicolumn{4}{|c|}{ Ho: diff $=0$} & \multicolumn{3}{|c|}{ degrees of freedom $=239$} \\
\hline \multicolumn{2}{|c|}{ Ha: diff $<0$} & \multicolumn{2}{|c|}{ Ha: diff $!=0$} & \multicolumn{2}{|c|}{ Ha: $\operatorname{diff}>0$} & \\
\hline \multicolumn{3}{|c|}{$\operatorname{Pr}(\mathrm{T}<\mathrm{t})=0.9730$} & $\mathbf{T}|>| \mathbf{t} \mid$ & \multicolumn{3}{|c|}{$\operatorname{Pr}(\mathrm{T}>\mathrm{t})=0.0270$} \\
\hline
\end{tabular}

\footnotetext{
**note: T test suggest there is adequate difference in the number of training being imparted by the two category banks i.e. public \& private sector bank
}

The difference in the training programmesbeing conducted by public and private sector banks exist depending upon other factors that may affect the interest of the employees to attend the same as 
trainings may have been scheduled for but how many turned to participate is the concern in the objective. In public sector banks the attitude of women had been that nothing will happen to their job even if the training programs are not being attended while in private sector banks women are more career cautious and think of their career growth which is possible only through attending pertinent training programs that may enhance their performance and role in achieving their duties and responsibilities.

As maximum of the women employees in the public sector banks are married and are in the age of 30-40 years their attitude towards attending training programs is very casual. The norms of the public sector banks clearly indicate the number of training to be conducted while private sector banks emphasis on the recognition of the training need.

Two-sample $t$ test with equal variances

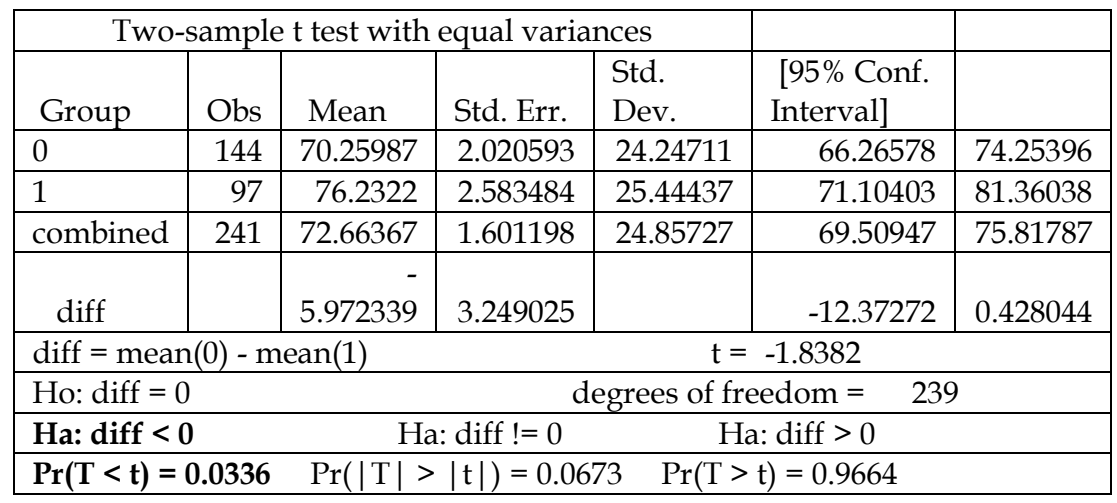

** note: $\mathrm{T}$ test suggest that there is difference in the number of productive training of two sector banks while the number of productive training is higher in private sector bank in comparison to public sector bank. (Pictorial histograms enclosed beneath)

. table bd, c(freq mean proportion sd proportion)

\begin{tabular}{|c|c|c|c|}
\hline BD & Freq. & mean $($ propor $\sim \mathrm{n})$ & sd(propor $\sim \mathrm{n})$ \\
\hline 0 & 144 & 70.25986 & 24.24711 \\
\hline 1 & 97 & 76.2322 & 25.44437 \\
\hline
\end{tabular}


In order to evaluate the variable of proportion trainings with our policy variable i.e. the evaluation of productivity of training programs to those attended we did One tail T-Test and found that there besides being significant difference in the number of training programmes conducted by public sector banks and the private sector banks with respect to the women employees as proved in Tables above depicts that the private banks though conduct less number of training programs as compared to public sector bank yet the effectiveness of the training programs is quite high among women employees. Therefore the null hypothesis is rejected since mean proportion on the proportion of productive training is high in private sector bank. Being effectiveness of training high it will definitely have positive impact on the growth of the banks leading to job satisfaction and enhancing the role of women in banks.

This evaluation is important to be assessed to measure the productivity of the training program which will have direct impact on the performance of the employees and indirect impact on the growth of the banks.

We used Poisson Regression primarily to check the relationship between the policy variable i.e proportions of productive training by bank on different outcome variable. The outcome variable is count variable. Using ordered model may not be practical since in some cases the outcome variable takes large number of values. However, without rely into only Poisson Regression we did robustness check by using Ordered Probit.

The Poisson Mode: $Y=X \beta+\varepsilon$

DESIG, EDU, AGE, GEN, AIY, EXP, MARITAL, TTRNG, PRODTRNG, PROPXBD, PROPXDESIG, PROPXQUAL, PROPXAIY, PROPXEXP, PROPORTION, BD

$\varepsilon=$ random error,

$\mathrm{Y}=0,1.2,3, \ldots$ count variable $=$ PIR, PTR, PHPY, PROBIPY, TRNGES, KNPTRNG, TRNGCGW, JRS, FBP, BPYM, PROMD PROBIPY PETRNG IMPT TRNGS TRNGES KNPTRNG TRNGCGW 


\section{Analysis of First Objective}

1. To analyze the effectiveness of training among women employees in private and public sector banks in metro city i.e. New Delhi.

To ascertain the first objective of the study, we tried to understand the effect of reward system on individual performance, team performance, considering better performers receive higher pay collaborated with the current performance related pay system to have direct impact on the productivity of training programs imparted that further contribute to encourage better performance and accomplishment of the goals and objective of the banks.

No other variable except age having direct significance to the effectiveness of productive training programs at $10 \%$ level of significance. The marginal effect (ME) on outcome i.e. individual performance rewarded is negative i.e. -0.13 . The result remains same for both Poisson Regression and ordered probit. Though the coefficient of proportion of productive training is positive but insignificant. When we tried to study the relationship policy of banks between better performers being paid high pay, the policy variable proportion came to be significant at $1 \%$. The interacting variable proportion with designation and proportion with age, qualification were are also found significant at $5 \%$.The Marginal efficiency effect of proportion is positive. The value is 0.45 . The marginal effect of the two significant independent variable is negative.

More or less it came forward that though private sector banks conducting less number of training programs yet their effectiveness of training programmes is quite high in comparison to public sector banks may be due to the need assessment methodology being highly accepted in private sector banks or the age variance of the women employees being employed in the private sector banks.

\section{Analysis of Second Objective}

To find the association between effectiveness of training and productivity of banks.

To ascertain the second objective of the study we tried to understand the significance level of the perspective that the 
training imparted by banks were upgrading the skills of the women employees. Among the women respondents from public sector bank only $46 \%$ believed that the training imparted by the banks adds to the upgrading of the skills of the employees while $42 \%$ strongly believed that the training imparted by private banks has significant effect. Overall $43 \%$ of the women respondents felt that the training programs do add to the skill enhancement of the employees.

Rest all the respondents strongly felt that the qualification and age were more significant to the proportion of the productiveness of training at $10 \%$. (as per poission regression result. The marginal effect is .005.

$33 \%$ of the women respondents of the public sector banks strongly believed that proper training can explore knowledge performance while $44 \%$ of women respondents have the same notion from private sector bank. Overall $48 \%$ believed that knowledge performance can be explored and can be utilized back at job after effective training.

Hence it was found that the productivity of training is directly linked to the qualification or the ages of the employee to the extent while other variables remaining constant.

In our analysis we found that on an average $33 \%$ of the women strongly agreed, $48 \%$ showed the sign of agreement to the concept while $7 \%$ either somewhat agreed or $7 \%$ were not sure.

\section{Analysis of Third Objective}

To evaluate the effectiveness of training programme in enhancing the role of women in banks.

To access whether good motivational factors like salary \& fringe benefits are integral part of job satisfaction for women working in banks. Training another factor leads to job enrichment/ performance and in turn it may enhance career growth and role of an employee at workplace.

The analysis of the variables like satisfaction from ones job and responsibilities, flexible benefit programs directing to pay the better performers and defined and clear rules, regulations of bank in 
determining the promotion policies will definitely have positive impact on the job description leading to their career growth and thereby enhancing the role of women in banks.

In our analysis, only the policy variable proportion of productive training and the proportionate annual income is positively significant to the bank's policy. The regressor aspect of annual income is positively significant at $5 \%$. The Marginal efficiency of proportion is 0.04 .

Further to our analysis, variable proportion is significant on the outcome variable PROMD. The regressor aiy is positively significant at $5 \%$ and the interaction between aiy and proportion is negatively significant at $5 \%$. The ME of proportion is 0.03 .

Thus from the analysis it is clear that 35\% from the public bank while $22 \%$ from the private bank believed that clear policies of bank contribute a lot to the enhancement of the role of women employees in banking sector. While overall 30\% agreed to the statement and $17 \%$ having no opinion about it.

It can be finally analysed that the effectiveness of training programs has to add to the enhancement of the role of women in banks but the result coming out is quite negligible. It means some problem in the policy formation of women advancement in banks is to be taken care for achievement of banks goals and objectives.

The analysis can be more clearly depicted in the graph showing the proportion of productive training being conducted by public and private sector banks.

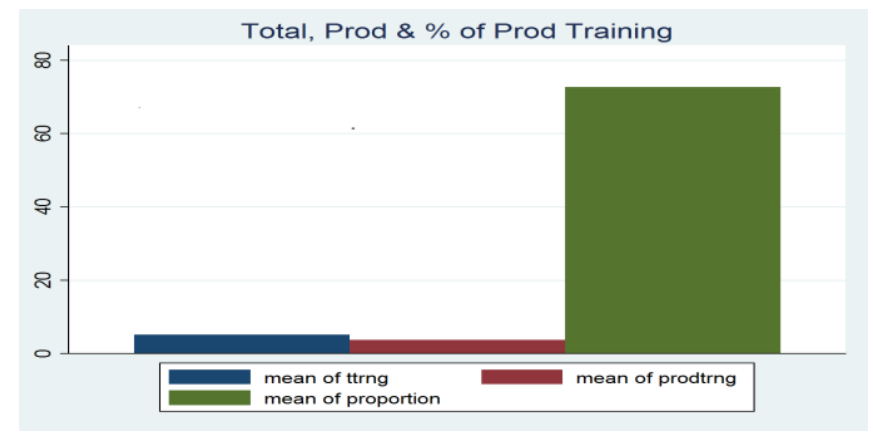

Fig: 2Analysis of Proportion of Training Attended by Women Employees 
The table shows the mean of total training programmes attended by women employees of private and public sector banks as $5 \%$. The mean of total training felt to be productive by women employees is only $3 \%$, quite less as compared to the total number of trainings being conducted/attended which means that though the trainings are being conducted for the women employees but the objectives of the training are not met properly. Anyhow the mean proportion of the productive training for women employees when computed together for both the banks came to be $70 \%$ may be due to the impact of need analysis done for training programmes by either of the bank.

Mean of the proportion of Productive training is calculated as $=$ (Mean of total productive training / Mean of total training) *100 (In absolute terms i.e. the proportion of successful training attended by women employees)

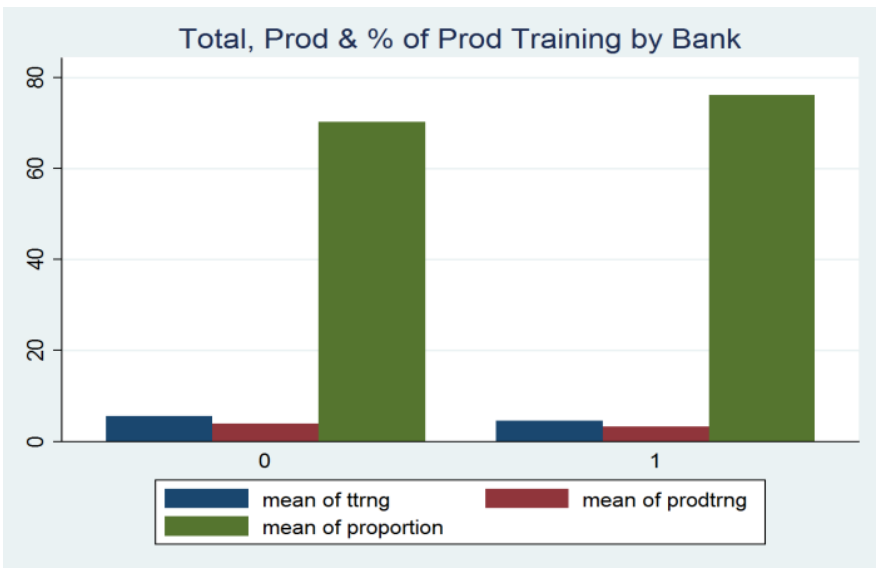

Fig: 3Analysis of Proportion of Productive Training Attended by Women Employees

The table shows the comparison between the two sector banks i.e. private and public

The mean of total training programmes attended by women employees of public sector banks is $5 \%$. Out of which only $3 \%$ of the women feel that the training programmes imparted to them 
were significant while the mean proportion of the productive training for women employees is computed to be about $65 \%$.

Similarly, the mean of the total training of private sector banks with regards to women attending the same is computed to be $4 \%$, out of which only $3 \%$ felt that the training programmes given to them with regards to their job requirements were productive. The mean of the proportion of training felt productive computed to be $75 \%$.

This shows that there is quite a difference in the training imparted by the two sector banks to their employees but the training imparted by private sector bank is though less in frequency yet considered to be more productive when compared to public sector banks.

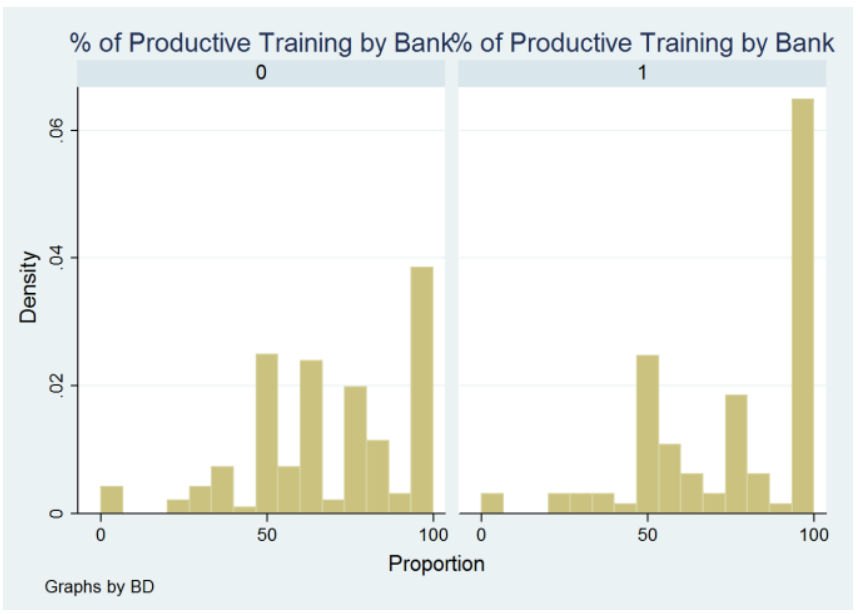

Fig: 4Analysis Showing Frequency of Responses of Women Employees on Training Programmes of Private and Public Sector Banks

0 stands for Public Sector Bank

1 stands for Private Sector Bank

As depicted in the histogram clearly indicate that among public sector banks the women employees with relative frequency .03 feel that $50 \%$ of the trainings designed and imparted to them are successful and women with relative frequency .04 are of the view 
that $100 \%$ training are able to come to their level of satisfaction that they feel will make them learn the job clearly.

While in the second adjacent histogram, depicting the proportion and density of total training programmes in private sector banks, women with relative frequency .025 employees are of the view that $50 \%$ of the training are able to met the objected they are designed for while relative frequency with .065 are of the view that the $100 \%$ training programmes designed by their private banks are taken care of and are designed keeping in view the women reliability of attending and attaining maximum benefit of the leaning concept of training programmes.

\section{Conclusion}

The purpose of this study is to observe the relationship between three HR Practices i.e. (Training and Development, Rewards, Recognition) and the employee job satisfaction in the public and the private sector banking organizations of a developing country.

Recognition and training and development are a key source of employee job satisfaction in public and the private sector banking organizations.

These HR Practices are also known as key drivers of employee performance. Training and development is one of the key elements of employee job satisfaction because it reduces the discrepancies in job tasks and enhances the job skills which in result motivates the employees and lead towards job satisfaction. Employees get extremely motivated through rewards and recognition and these two factors lead towards employee motivation and research shows that highly motivated employees are the most satisfied employees and also the high performers.

Normally managers don't focus upon the relationship of rewards and job satisfaction, recognition and job satisfaction or training and development and job satisfaction. Every individual employee wants satisfaction at job but organization is wasting its resources by focusing on wrong HR practices for employee job satisfaction.

The unsatisfied employees of public sector organizations, when switch to private sector, they have been observed to be much more 
satisfied, therefore it is very important for the managers to know which HR Practices keep them satisfied and how much important role rewards, recognition and training and development have regarding employee job satisfaction.

\section{Effect of Training \& Development on Women Employees}

1. Employees who are trained regularly are well motivated and have enhanced confidence and self - esteem.

2. Training \& development prepare \&enhance employee's knowledge \& skills to enable them to adopt to new technology, the changes in the organisations \& the working environment.

3. Training and development also creates a pool of employees for promotion or to replace employees who have left the organization.

4. Training and development enhances job satisfaction because the employees know what is expected of them as they are also equipped with the knowledge and tools to perform their job efficiently.

5. Cross-training and multitasking of employees allows them to perform tasks other than what is relegated to them and gives them a sense of importance in the organization and feelings of security.

\section{Suggestions and Implications}

- Require all staff to have a career discussion with their manager/supervisor that includes an annual training and development plan.

- Train managers to effectively and objectively use the performance and development process for both men and women (eg how to give positive and negative performance feedback to female and male staff).

- Encourage managers to discuss training and development interests and opportunities for the future with both female and male employees. 
- Hold managers accountable for implementing the development plan by including it in their workplace and/or performance agreement.

- Challenge management assumptions about why women are not provided with the same access to training and development as their male peers.

- Encourage staff to participate in learning experiences that build diverse skills and broaden career options.

- Recognizing and enhancing women's actual and potential role in productive and social activities and in turn their share in the contribution to the national development process

- In order to benefit from productive and other developmentoriented programs it becomes essential to reduce social, legal and economic constraints that depress women's ability to recognize her role

- Improving the effectiveness of banks responsible for fostering the social and economic participation of women in the development process.

\section{References}

Ambavane, A . (2011). A study of efficacy of staff training programmes in urban cooperative banks in raigad districtMaharashtra. International Referred Journal. II (20), 35-36

Gopal, A. (2012). Engage Employees or Fail-Talent Strategy. People Matters. III(10), 40-41.

Ballot, G., F. Fakhfakh and E. Taymaz. (2001). "Firms' Human Capital, R\&D and Performance: A Study on French and Swedish Firms". Labour Economics. 8(4), 443-462.

Martinez. E. \& Saikia, R. (2012). Workplace 2030.People Matters. III(10), 42-51

Gupta P \& Sharma, N. (2011). Employees Attitude towards and Satisfaction with Performance based Payment Practices in the Indian Banking Sector. Journal of IPEM. 5(1), 33-38.

Gupta S.P. (2012). Statistical Methods. Delhi. Sultan Chand and Sons. 
Mohammed, A. (2011). "A study on perception of trainers regarding effectiveness of training programmes in banking sector." Asia Pacific Review Journal. 7 (1).

Bhaskar, P.V. (2004). Human Resource Management in Banks: Past and Present Scenario. HRM Review.4(3),41-47.

Rowden, R.W. (2005). Exploring methods to evaluate the return-oninvestment from training, Business Forum. 27(1) 31-36.

Thakur M. (2007), Job Satisfaction in banking: A study of private and public sector banks. The ICFAI Journal of Bank Management. 6(4), 60-68. 